\title{
Synteza celulaz w hodowlach bakterii Paenibacillus sp. wyizolowanych z ryzosfery
}

\author{
Jakub Dobrzyński ${ }^{1}$, Monika Sitarek ${ }^{4}$, Patrycja Słodownik ${ }^{1}$, \\ Urszula Jankiewicz², Dariusz Gozdowski ${ }^{3}$, Ewa B. Górska ${ }^{1}$ \\ 1 Samodzielny Zakład Biologii Mikroorganizmów, Szkoła Główna Gospodarstwa Wiejskiego w Warszawie \\ Nowoursynowska 159, 02-776 Warszawa, p.slodownik@onet.pl \\ 2 Wydział Rolnictwa i Biologii, Szkoła Główna Gospodarstwa Wiejskiego w Warszawie \\ Katedra Biochemii \\ 3 Wydział Rolnictwa i Biologii, Szkoła Główna Gospodarstwa Wiejskiego w Warszawie \\ Katedra Doświadczalnictwa i Bioinformatyki \\ 4 Wydział Ogrodnictwa, Biotechnologii i Architektury Krajobrazu, Szkoła Główna Gospodarstwa Wiejskiego w Warszawie \\ Katedra Roślin Warzywnych i Leczniczych
}

\section{Streszczenie}

Z gleby ryzosferowej jabłoni, wiśni i truskawki nawożonej kompostami przygotowanymi na bazie miału z węgla brunatnego z dodatkiem grzybni Basidiomycota, wyizolowano sześć szczepów bakterii względnie beztlenowych, przetrwalnikujących zdolnych do rozkładu celulozy. Na podstawie morfologii, cech biochemicznych i sekwencji 165 rRNA izolaty sklasyfikowano do gatunków z rodzaju Paenibacillus. W pożywkach wybiórczych z dodatkiem bibuły filtracyjnej (FP) i karboksymetylocelulozy (CMC) badane izolaty syntetyzowały enzymy, które hydrolizują celulozę amorficzną i krystaliczną. Badane izolaty w 14 i 28 -dniowych hodowlach w pożywce z karboksymetylocelulzą (CMC) produkowały odpowiednio od $0 \mathrm{mU}$ do 10,87 mU oraz od 10,73 do 21,13 mU CMCazy (karboksymetylocelulazy). Najwyższą aktywność enzymów scukrzających celulozę (FPazy) w pożywce z CMC wykazano w 14-dniowych hodowlach P. lautus EG_11 - 75,6 mU, Paenibacillus sp. EG_17 - 57,6 mU oraz P. woosongensis EG_15 - 38,9 mU. W pożywce z dodatkiem bibuły filtracyjnej (FP), najwyższą produkcję CMCazy i FPazy odnotowano w hodowlach $P$. lautus EG_11 - odpowiednio 79,85 i $118,83 \mathrm{mU}$.

\section{Stowa kluczowe}

CMCaza, FPaza, Paenibacillus

\section{Wstęp}

Celuloza zbudowana jest z cząsteczek $\beta$-Dglukozy, połączonych wiązaniami $\beta$-1,4-glikozydowymi, uformowanymi w tzw. regiony krystaliczne i amorficzne. Obecność regionów krystalicznych warunkuje trudność w rozkładzie celulozy w środowisku przyrodniczym (Akaracharanya i in. 2014). Enzymy rozkładające celulozę należące do klasy hydrolaz O-glikozydowych są wytwarzane $\mathrm{w}$ środowisku przez mikroorganizmy należące do różnych grup systematycznych (Beguin, Aubert 1994). Do bakterii przetrwalnikujących biorących 
udział w rozkładzie celulozy w warunkach względnie beztlenowych należą bakterie z rodzaju Bacillus i Paenibacillus. Mikroorganizmy te hydrolizują zarówno celulozę krystaliczną, jak i amorficzną dzięki syntezie endo- $\beta$-1,4-glukanazy (EC 3. 2. 1. 4), egzoglukanazy, syn. 1,4- $\beta$-glukan celobiohydrolazy (EC 3. 2. 1. 91) oraz celobiazy, syn. $\beta$ glukozydazy (EC 3. 2. 1. 21) (Horn i in. 2012).

Strefa przykorzeniowa roślin (ryzosfera) zasiedlana jest licznie przez mikroorganizmy, w tym przez bakterie z rodzaju Bacillus i Paeniabacillus (Święcicka, Hauschild 1996). Duża różnorodność mikroorganizmów w tej strefie jest determinowana przez wydzieliny korzeniowe, w tym śluz zawierający związki organiczne będące źródłem węgla i energii dla drobnoustrojów. Dodatkowo komórki graniczne korzeni złuszczając się stanowią źródło celulozy, z której mogą korzystać bakterie np. z rodzaju Paenibacillus wytwarzające enzymy celulolityczne (Barlow 2003).

Do tej pory wyizolowano z różnych środowisk i opisano wiele przetrwalnikujących bakterii z rodzaju Paenibacillus degradujących celulozę w warunkach in vivo i in vitro, m.in.: P. polymyxa - wcześniej Bacillus polymyxa (Fogarty i in. 1973), P. favisporus (Velazquez i in. 2004), P. barcinonensis (Sanchez i in. 2005), P. xylanilyticus (Rivas i in. 2005), P. curdlanolyticus (Pason i in. 2006), P. panacisoli (Ten i in. 2007), Paenibacillus thailandensis, P. septentrionalis, P. nanensis, P. montaniterrae (Khianngam i in. 2009), P. cellulositrophicus (Akaracharanya i in. 2009), P. sacheonensis (Moon i in. 2011).

W ostatnim czasie wzrosło zainteresowanie zdolnością Paenibacillus $i$ Bacillus do rozkładu celulozy krystalicznej. Głównym tego powodem jest możliwość wykorzystania celulaz syntetyzowanych przez te bakterie w wielu dziedzinach nauki i przemysłu np. w przemyśle spożywczym, tekstylnym, genetyce, medycynie, czy w biotechnologii (Beukes, Pletschke 2006; Waeonukul i in. 2009).

Celem badań była izolacja bakterii z rodzaju Paenibacillus z ryzosfery wybranych roślin i ich identyfikacja oraz oznaczenie zdolności do syntezy enzymów celulolitycznych.

\section{Metody i materiały}

Szczepy bakterii wyizolowano ze strefy ryzosferowej wiśni, jabłoni i truskawki, które nawożono kompostami przygotowanymi na bazie miału $\mathrm{z}$ węgla brunatnego $\mathrm{z}$ dodatkiem grzybni Basidiomycota (Pleuortus ostreatus, Lentinus edodes). Rośliny były hodowane na poletkach doświadczalnych założonych w Skierniewicach przez pracowników Wydziałowej Stacji Doświadczalnej. W celu izolacji szczepów 10 g świeżych korzeni wraz z glebą zawieszono w $100 \mathrm{ml}$ soli fizjologicznej $(0,85 \% \mathrm{NaCl})$, a następnie wytrząsano przez 20 minut i poddawano pasteryzacji w temp. $85^{\circ} \mathrm{C}$ przez 15 minut. Następnie $1 \mathrm{ml}$ zawiesiny wsiewano jałowo do pożywki Park'a (Vardavakis 1989) z FP (bibuła filtracyjna) i inkubowano w temp. $28^{\circ} \mathrm{C}$ przez 4 tygodnie. W celu izolacji bakterii 28 -dniowe hodowle pasażowano wielokrotnie w pożywce Park'a (ciekłej lub stałej) z dodatkiem lub bez dodatku ekstraktu drożdżowego.

Wstępną identyfikację szczepów przeprowadzono na podstawie obserwacji $\mathrm{w}$ mikroskopie świetlnym preparatów trwałych komórek bakterii hodowanych na agarze odżywczym przez 24 godziny w temp. $28^{\circ} \mathrm{C}$ oraz sprawdzając ich zdolność do syntezy katalazy. Cechy biochemiczne drobnoustrojów z rodzaju Bacillus $i$ Paenibacillus badano z zastosowaniem testów API $50 \mathrm{CHB}$ firmy bioMerieux.

Przynależność izolatów do rodzaju oznaczono analizując sekwencję 16S rRNA badanych bakterii. Do analizy zastosowano uniwersalne startery $27 \mathrm{~F}$ i $1401 \mathrm{R}$. Jako matrycy użyto genomowego DNA wyizolowanego przy użyciu Genomic DNA Purification Kit (Fermentas) z komórek późnej fazy logarytmicznego wzrostu hodowli bakterii. Oczyszczony produkt PCR został zsekwencjonowany w Pracowni Sekwencjonowania DNA i Syntezy Oligonukleotydów Instytutu Biochemii i Biofizyki Polskiej Akademii Nauk. Otrzymane sekwencje nukleotydowe porównano z sekwencjami 
Tabela 1. Wyizolowane szczepy

\begin{tabular}{ll}
\hline Zidentyfikowane izolaty (numer akcesyjny) & Najbardziej pokrewne szczepy (numer akcesyjny) \\
\hline Paenibacillus sp. EG_8 (AB903906) & Paenibacillus sp. BXC (J0904538) \\
\hline Paenibacillus lautus EG_9 (AB903908) & Paenibacillus sp. Sd-7 (JF508413) \\
\hline Paenibacillus lautus EG_11 (AB902952) & Paenibacillus lautus MPF 112 (FN677987) \\
\hline Paenibacillus lautus EG_12 (AB903910) & Paenibacillus sp. H28-08 (AM162307) \\
\hline Paenibacillus woosongensis EG_15 (AB902951) & Paenibacillus sp. SDCB10 (JN617219) \\
\hline Paenibacillus sp. EG_17 (AB903911) & Paenibacillus sp. Sd-7 (JF508413) \\
\hline
\end{tabular}

znajdującymi się bazach w GenBanku/ EMBL (European Molecular Biology Laboratory)/DDBJ (DNA Data Bank of Japan) z wykorzystaniem programu BLAST (Basic Local Alignment Search Tool).

Zdolność wyizolowanych bakterii do syntezy celulaz badano w pożywce wg Dubos'a (1928) z zastosowaniem dwóch źródeł celulozy: pasków bibuły filtracyjnej Whatman nr $1-$ FP $(1 \times 6 \mathrm{~cm})$ i $1 \%$ roztworu CMC (karboksymetylocelulza). W tym celu do pożywki (6 ml) wsiewano o,5 $\mathrm{ml}$ inokulum badanych izolatów (gęstość 7 w skali McFarlanda) przygotowanego w roztworze soli fizjologicznej (o,85\% NaCl). Hodowle założono w sześciu powtórzeniach dla każdego izolatu. Badania wstępne przeprowadzono w pożywce Dubos'a z ekstraktem drożdżowym (o,05\%). Produkcję CMCazy i FPazy mierzono po 14 i 28 dniach hodowli w temp. $28^{\circ} \mathrm{C}$, metodą spektrofotometryczną (Ghose 1987). Za jednostkę aktywności (U) CMCazy i FPazy przyjęto ilość enzymu, która w warunkach doświadczenia uwalnia ilość cukrów redukujących równoważną $1 \mu$ molowi glukozy uwolnionej w ciągu 1 minuty w warunkach oznaczenia.

Weryfikację wyników badań przeprowadzono z wykorzystaniem jednoczynnikowej analizy wariancji stosując program Statgraphics plus ver. 4.o. Grupy jednorodne wyróżniano testem Fishera przy $\alpha=0,05$.

\section{Wyniki}

Badane izolaty to względnie beztlenowe, przetrwalnikujące bakterie cylindryczne, Gram+, produkujące katalazę, stąd wstępnie oznaczono je do rodzaju Bacillus i $\mathrm{Pa}$ enibacillus, natomiast badania molekularne wykazały, że izolaty należą do rodzaju Paenibacillus (Tab. 1.).

Badane izolaty asymilowały D-galaktozę, D-glukozę, D-fruktozę, D-mannitol, $\mathrm{N}$-acetyloglukozaminę, eskulinę, D-celobiozę, D-maltozę, skrobię. Natomiast żaden z izolatów nie asymilował: glicerolu, erytrytolu, D-arabinozy, L-ksylozy, D-adonitolu, L-sorbozy, L-ramnozy, dulcytolu, inozytolu, D-sorbitolu, M- $\alpha$-D-Mannopiranozyd, D-tagtozy, D-fukozy, L-fukozy, D-arabtiolu, L-arabitolu, glukonianu potasu, 2-ketoglukonianu potasu, 5-ketoglukonianu potasu (Tab. 2.).

Wszystkie izolaty hodowane w pożywce z dodatkiem CMC wykazały zbliżoną produkcję CMCazy, zarówno w 14 jak i 28 dniu hodowli (Tab. 3.). Produkcja FPazy na tym samym substracie była największa w hodowli 14-dniowej P. lautus EG_11, Paenibacillus sp. EG_17 i P.woosongensis EG_15 (Tab. 4.). Produkcja FPazy po 28 dniach hodowli na CMC P. lautus EG_12 i Paenibacillus sp. EG_17 była porównywalna i istotnie większa w stosunku do pozostałych szczepów (Tab. 4.). 
Tabela 2. Charakterystyka biochemiczna izolatów

\begin{tabular}{|c|c|c|c|c|c|c|c|c|c|c|c|c|c|c|c|}
\hline \multirow{2}{*}{ L.p. } & \multirow{2}{*}{$\begin{array}{l}\text { Cecha } \\
\text { biochemiczna }\end{array}$} & \multicolumn{6}{|c|}{ Numer szczepu } & \multirow{2}{*}{ L. p. } & \multirow{2}{*}{$\begin{array}{l}\text { Cecha } \\
\text { biochemiczna }\end{array}$} & \multicolumn{6}{|c|}{ Numer szczepu } \\
\hline & & 8 & 9 & 11 & 12 & 15 & 17 & & & 8 & 9 & 11 & 12 & 15 & 17 \\
\hline 1 & Kontrola & - & - & - & - & - & - & 26 & Esukulina & + & + & + & + & + & + \\
\hline 2 & Glicerol & - & - & - & - & - & - & 27 & Salicyna & + & - & + & + & + & + \\
\hline 3 & Erytrytol & - & - & - & - & - & - & 28 & D-celobioza & + & + & + & + & + & + \\
\hline 4 & D-arabinoza & - & - & - & - & - & - & 29 & D-maltoza & + & + & + & + & + & + \\
\hline 5 & L-arabinoza & - & + & + & + & + & + & 30 & D-laktoza & - & + & + & + & + & + \\
\hline 6 & D-ryboza & - & + & + & + & + & + & 31 & D-melibioza & - & + & + & + & + & + \\
\hline 7 & D-ksyloza & - & + & + & + & + & - & 32 & D-sacharoza & - & + & + & + & + & + \\
\hline 8 & L-ksyloza & - & - & - & - & - & - & 33 & D-trehaloza & + & + & - & + & + & + \\
\hline 9 & D-adonitol & - & - & - & - & - & - & 34 & Inulina & - & - & + & - & - & - \\
\hline 10 & $\begin{array}{l}\text { Metylo- } \beta \text {-D- } \\
\text { ksylopiranozyd }\end{array}$ & - & + & - & - & - & + & 35 & D-melesytoza & + & - & - & - & - & - \\
\hline 11 & D-galaktoza & + & + & + & + & + & + & 36 & D-rafinoza & - & + & + & + & + & + \\
\hline 12 & D-glukoza & + & + & + & + & + & + & 37 & Skrobia & + & + & + & + & + & + \\
\hline 13 & D-fruktoza & + & + & + & + & + & + & 38 & Glikogen & + & + & - & + & + & + \\
\hline 14 & D-mannoza & - & + & + & + & + & + & 39 & Ksylitol & $\cdot$ & - & - & & $\cdot$ & - \\
\hline 15 & L-sorboza & - & - & - & - & - & - & 40 & Gencjobioza & + & - & - & - & - & + \\
\hline 16 & L-ramnoza & - & - & - & - & - & - & 41 & D-turanoza & - & - & - & - & - & + \\
\hline 17 & Dulcytol & - & - & - & - & - & - & 42 & D-liksoza & - & - & - & - & + & - \\
\hline 18 & Inozytol & - & - & - & - & - & - & 43 & D-tagatoza & - & - & - & - & - & - \\
\hline 19 & D-Mannitol & + & + & + & + & + & + & 44 & D-fukoza & - & - & - & - & - & - \\
\hline 20 & D-Sorbitol & - & - & - & - & - & - & 45 & L-fukoza & - & - & - & - & - & - \\
\hline 21 & $\begin{array}{l}\text { M-a-D- } \\
\text { Mannopiranozyd }\end{array}$ & - & - & - & - & - & - & 46 & D-arabitol & - & - & - & - & - & - \\
\hline 22 & $\begin{array}{l}\text { Metylo-a-D- } \\
\text { glukopiranozyd }\end{array}$ & - & - & - & + & - & - & 47 & L-arabitol & - & - & - & - & - & - \\
\hline 23 & $\begin{array}{l}\mathrm{N} \text { - acetyloglukoza- } \\
\text { mina }\end{array}$ & + & + & + & + & + & + & 48 & $\begin{array}{l}\text { Glukonian } \\
\text { potasu }\end{array}$ & & - & - & - & - & - \\
\hline 24 & Amigdalina & + & + & + & + & + & - & 49 & $\begin{array}{l}\text { 2-ketoglukonian } \\
\text { potasu }\end{array}$ & - & - & - & - & - & - \\
\hline 25 & Arbutyna & - & - & + & - & + & - & 50 & $\begin{array}{l}\text { 5-ketoglukonian } \\
\text { potasu }\end{array}$ & - & - & - & - & - & - \\
\hline
\end{tabular}

Spośród badanych izolatów tylko P.lautus EG_11 w hodowli 14 dniowej w pożywce z FP produkował enzymy celulolityczne. Po 28 dniach inkubacji produkcję FPazy na tym substracie oznaczono dla wszystkich szczepów, z wyjątkiem P. lautus EG_9, natomiast CMCazy po 28 dniach inkubacji nie 
Tabela 3. Produkcja CMCazy w hodowlach izolatów (w pożywce Dubos’a z ekstraktem drożdżowym i zastosowanymi źródłami celulozy). Różne litery w tej samej kolumnie oznaczają różnice statystycznie istotne na poziomie $\alpha=0,05$.

\begin{tabular}{lcccc}
\hline \multirow{2}{*}{ Izolaty } & \multicolumn{2}{c}{ Karboksymetyloceluloza } & \multicolumn{2}{c}{ Bibuła filtracyjna } \\
\cline { 2 - 5 } & $\begin{array}{c}\text { 14-dzień hodowli } \\
(\mathrm{mU})\end{array}$ & $\begin{array}{c}28-\text { dzień hodowli } \\
(\mathrm{mU})\end{array}$ & $\begin{array}{c}\text { 14-dzień hodowli } \\
(\mathrm{mU})\end{array}$ & $\begin{array}{c}28 \text { - dzień hodowli } \\
(\mathrm{mU})\end{array}$ \\
\hline Paenibacillus sp.EG_8 & $10,87 \mathrm{~b}$ & $11,47 \mathrm{a}$ & $0 \mathrm{a}$ & $0 \mathrm{a}$ \\
\hline Paenibacillus lautusEG_9 & $0 \mathrm{a}$ & $10,73 \mathrm{a}$ & $0 \mathrm{a}$ & $1,25 \mathrm{a}$ \\
\hline Paenibacillus lautus EG_11 & $7,4 \mathrm{ab}$ & $18,8 \mathrm{a}$ & $70,6 \mathrm{~b}$ & $79,85 \mathrm{~b}$ \\
\hline Paenibacillus lautus EG_12 & $6,73 \mathrm{ab}$ & $12,23 \mathrm{a}$ & $0 \mathrm{a}$ & $0 \mathrm{a}$ \\
\hline Paenibacillus woosongensis EG_15 & $9,9 \mathrm{~b}$ & $21,13 \mathrm{a}$ & $0 \mathrm{a}$ & $13,36 \mathrm{a}$ \\
\hline Paenibacillus sp. EG_17 & $6,2 \mathrm{ab}$ & $16,17 \mathrm{a}$ & $0 \mathrm{a}$ & $9,48 \mathrm{a}$ \\
\hline NIR $_{\mathrm{a}=0,05}$ & 8,103 & 19,593 & 1,69085 & 34,091 \\
\hline
\end{tabular}

Tabela 4. Produkcja FPazy w hodowlach izolatów (w pożywce Dubos'a z ekstraktem drożdżowym i zastosowanymi źródłami celulozy) . Różne litery w tej samej kolumnie oznaczają różnice statystycznie istotne na poziomie $\alpha=0,05$.

\begin{tabular}{lcccc}
\hline \multirow{2}{*}{ Izolaty } & \multicolumn{2}{c}{ Karboksymetyloceluloza } & \multicolumn{2}{c}{ Bibuła filtracyjna } \\
\cline { 2 - 5 } & $\begin{array}{c}\text { 14-dzień hodowli } \\
(\mathrm{mU})\end{array}$ & $\begin{array}{c}28 \text { - dzień hodowli } \\
(\mathrm{mU})\end{array}$ & $\begin{array}{c}\text { 14-dzień hodowli } \\
(\mathrm{mU})\end{array}$ & $\begin{array}{c}\text { 28- dzień hodowli } \\
(\mathrm{mU})\end{array}$ \\
\hline Paenibacillus sp. EG_8 & $2,63 \mathrm{a}$ & $4,5 \mathrm{a}$ & $0 \mathrm{a}$ & $1,92 \mathrm{ab}$ \\
\hline Paenibacillus lautus EG_9 & $4,5 \mathrm{a}$ & $4,2 \mathrm{a}$ & $0 \mathrm{a}$ & $0 \mathrm{a}$ \\
\hline Paenibacillus lautus EG_11 & $75,6 \mathrm{c}$ & $0 \mathrm{a}$ & $118,83 \mathrm{~b}$ & $10,83 \mathrm{ab}$ \\
\hline Paenibacillus lautus EG_12 & $11,53 \mathrm{a}$ & $38,5 \mathrm{~b}$ & $0 \mathrm{a}$ & $1,5 \mathrm{ab}$ \\
\hline Paenibacillus woosongensis EG_15 & $38,9 \mathrm{~b}$ & $13,33 \mathrm{a}$ & $0 \mathrm{a}$ & $0,73 \mathrm{ab}$ \\
\hline Paenibacillus sp. EG_17 & $57,55 \mathrm{bc}$ & $42,47 \mathrm{~b}$ & $0 \mathrm{a}$ & $2,95 \mathrm{ab}$ \\
\hline NIR $\mathrm{a}_{\mathrm{a}=0,05}$ & 24,174 & 20,549 & 9,861 & 10,779 \\
\hline
\end{tabular}

syntetyzowały szczepy $P$. lautus EG_12 i Paenibacillus sp. EG_8 (Tab. 3.).

\section{Dyskusja}

W literaturze istnieje kilka pozycji opisujących szczepy Paenibacillus o podobnych cechach biochemicznych do izolatów opisanych przez autorów. Liang i in. (2014) wykazali, że wyizolowany przez nich szczep Paenibacillus terrae ME27-1 asymiluje: fruktozę, eskuklinę, D-celozbiozę, D-maltozę, skrobię, natomiast nie wykorzystuje: glicerolu, erytrolu, D-arabinozy, L-sorbozy, L-ramnozy, dulcytolu, inozytolu, Dsorbitolu, ksylitolu, D-tagatozy, D-fukozy, $\mathrm{D}$-arabitolu, co koresponduje z cechami biochemicznymi szczepów wyizolowanych przez autorów. Natomiast zgodność wyników z wyjątkiem szczepu Paenibacillus sp. EG_8 stwierdzono dla: L-arbinozy, D-rybozy, D-mannozy, D-laktozy, D-melibiozy, D-rafinozy. Bakterie z rodzaju Bacillus i $\mathrm{Pa}$ enibacillus badane przez Akaracharanya (Akaracharanya i in.2014) są zdolne do wykorzystywania takich związków jak: eskulina, D-celobioza, D-maltoza, skrobia, glicerol, L-sorboza, L-ramnoza, inozytol, d-sorbitol. Ponadto takie same wyniki z wyjątkiem szczepu Paenibacillus sp. EG_8 otrzymanoprzy związkach: L-arabinoza, D-laktoza, D-melibioza.

Wśród drobnoustrojów celulolitycznych z rodzaju Paenibacillus stwierdza się zdolność do hydrolizy celulozy dzięki syntezie 
przez nie kompleksu celulazy, który złożony jest z: endoglukanaz, egzoglukanaz i celobiazy (Emtiazi i in. 2007). Większość prac opisująca bakterie z rodzaju Paenibacillus dotyczy produkcji endoglukanaz określanej również jako produkcja karboksymetylocelulazy (Akaracharanya i in. 2009; Kumar i in. 2012). Jednak w ostatnim czasie większą uwagę poświęca się badaniom nad produkcją celulaz hydrolizujących regiony krystaliczne celulozy m.in. awicelazie (Subramaniyan, Prema 1999; Waeonukul i in. 2009).

Produkcja celulaz w hodowlach badanych izolatów zależała od źródła celulozy. Szczepy hodowane w pożywce mineralnej z dodatkiem CMC jako źródło węgla produkowały zbliżone ilości CMCazy oscylujące w graniach o - $21 \mathrm{mU}$. Podobne wartości otrzymali Akaracharanya i in. (2014), produkcja CMCazy wyizolowanych przez nich szczepów Paenibacillus sp. hodowanych z dodatkiem CMC wynosiła od $1 \mathrm{mU}$ do $8 \mathrm{mU}$. Natomiast wyższe aktywności enzymów celulolitycznych w hodowlach Paenibacillus z dodatkiem CMC stwierdzili Emtiazi i in. (2007). Produkcja CMCazy i FPazy badanych przez nich szczepów Paenibacillus sp. E, Paenibacillus sp. H i Paenibacillus sp. SH oscylowała w granicach od $200 \mathrm{mU}$ do 5000 mU w zależności od czasu trwania hodowli. Na podłożu z dodatkiem FP najwyższą produkcję zarówno FPazy, jak i CMCazy stwierdzono dla szczepu Paenibacillus lautus EG_11. Zbliżone wyniki uzyskali we wcześniejszych badaniach (Górska i in. 2001). Wyizolowany przez nich szczep Bacillus polymyxa (obecnie Paenibacillus polymyxa) hodowany z dodatkiem FP jako źródło celulozy produkował CMCazę w ilości $35 \mathrm{mU} /$ ml. Produkcja CMCazy przez ten szczep jest zbliżona do produkcji szczepu Paenibacillus lautus EG_11, która wynosi 23,6 mU. Nieco wyższe wartości syntezy FPazy odnotowali Sharma i in. (2013) w hodowli P. mucilaginosus B5. Badany przez nich szczep hodowany $\mathrm{z}$ dodatkiem odpadów ligninocelulozowych z Dandracalamus stritcus wykazał produkcję FPazy - 480 mU, a z dodatkiem odpadów z Bobma ceiba - 504 mU, co jest około pięciokrotnie wyższą aktywnością od najlepszego szczepu Paenibacillus lautus EG_11 $118,83 \mathrm{mU}$.

\section{Podsumowanie}

Z roku na rok zwiększa się ilość odpadów ligninocelulozowych, które do środowiska trafiają wraz z produktami ubocznymi leśnictwa, przemysłu tekstylnego czy rolnictwa (Denisiuk 2008). Odpady te ze względu na ich skład chemiczny w środowisku przyrodniczym mogą ulegać rozkładowi trwającemu niekiedy kilkanaście i więcej lat (Bednarski, Respa 2001). W związku z powyższym coraz więcej badań prowadzonych jest nad syntezą bakteryjnych i grzybowych enzymów celulolitycznych i ligninolitycznych, które znalazłyby zastosowanie w gospodarce człowieka do utylizacji odpadów ligninocelulozowych lub innego wykorzystania. Wyizolowane przez autorów szczepy bakterii syntetyzują CMCazy i FPazy, dlatego potencjalnie moga być użyte do przygotowania preparatu enzymatycznego do degradacji odpadów ligninocelulozowych.

\section{Bibliografia}

Akaracharanya A., Lorliam W., Tanasupawat S., Lee K.C., Lee J.S, 2009, Paenibacillus cellulositrophicus sp. nov., a cellulolytic bacterium from Thai soil, Int. J. Syst. Evol. Micr. 59, 2680-2684.

Akaracharanya A., Taprig T., Sitdhipol J., Tanasupawat S., 2014, Characterization of cellulase producing Bacillus and Paenibacillus strains from Thai soils, J. Appl. Pharm. Sci. 4, 6-11.

Barlow P.W., 2003, The root cap: Cell dynamics, cell differentiation and cap function, J.Plant growth Regul. 21, 261-286.

Bednarski W., Repsa A., 2001, Food biotechnology, wyd. WNT, Warszawa.

Beguin P., Aubert J.P., 1994, The biological degradation of cellulose [Review], FEMS Microbiol. Rev. vol. 13, 25-58.

Beukes N., Pletschke B.I., 2006, Effect of sulfur-containing compounds on Bacillus cellulosome-associated 'CMCase' and 'Avicelase' activities, FEMS Microbiol. Lett. 264, 226-231.

Denisiuk W., 2008, Straw. The potential of mass and energy, Agr. Eng, vol. 100, 23-30. (in Polish). 
Dubos R.J., 1928, The decomposition of cellulose by aerobic bacteria, J. Bacteriol. vol. 15: 223-234. Emtiazi G., Pooyan M., Shamalnasab M., 2007, Cellulase activities in nitrogen fixing Paenibacillus isolated from soil in n-free media, World J. Agr. Sci., vol. 3, 602-608.

Fogarty W.M., Griffin P.L., 1973, Some preliminary observations on the production and properties of a cellulolytic enzyme elaborated by Bacillus polymyxa, Biochem. Soci. Trans, vol. 1, 1297-1298

Ghose T.K., 1987, Measurement of cellulase activities, Pure Appl. Chem. vol. 59, 257-268.

Górska, E., Tudek B., Russel S., 2001, Degradation of cellulose by nitrogen-fixing strain of Bacillus polymyxa, Pol. J. Microbiol. vol. 50, 129-137.

Horn S.J., Vaaje-Kolstad G., Westereng B., Eijsink V.G.H., 2012, Novel enzymes for the degradation of cellulose, Biotechnol. Biofuels, vol. 5, 45-57.

Khianngam S., Akaracharanya A., Tanasupawat S., Lee K.C., Lee J.S., 2009, Paenibacillus thailandensis sp. nov. and Paenibacillus nanensis sp. nov., xylanase-producing bacteria isolated from soil, Int. J. Syst. Evol. Micr. vol. 59, 564-568.

Kumar D., Ashfaque M., Muthukumar M., Singh M., Garg N., 2012, Production and characterization of carboxymethyl celllulase from Paenibacillus polymyxa using mango peel as substrate, J. Eviron. Biol. vol. 33, 81-84.

Liang Y.L., Zhang Z., Wu M., Wu Y., Feng J.X., 2014, Isolation, screening, and identification of cellulolytic bacteria from natural reserves in the subtropical region of china and optimization of cellulase production by Paenibacillus terrae ME27-1, Biomed Res. Int., 1-13.

Moon J.C., Jung X.J., Jung J.H., Jung H.S., Cheong Y.R., Jeon C.O., Lee K.O., Lee S.Y., 2011, Paenibacillus sacheonensis sp. nov., a xylanolytic and cellulolytic bacterium isolated from tidal flat sediment, Int. J. Syst. Evol. Micr. vol. 61, 2753-2757.

Pason P., Kyu K.L, Ratanakhanokchai K., 2006, Paenibacillus curdlanolyticus strain B-6 xylanolyticcellulolytic enzyme system that degrades insoluble polysaccharides, Appl. Environ. Microbiol. vol. 72, 2483-2490.
Rivas R., Mateos P.F., Martínez-Molina, E. Velázquez. 2005. Paenibacillus phyllosphaerae sp. nov., a xylanolytic bacterium isolated from the phyllosphere of Phoenix dactylifera, Int. J. Syst. Evol. Micr., vol. 55, 743-746.

Sánchez M.M., Fritze D., Blanco A., Spröer C., Tindall B.J., Schumann P., Kroppenstedt R.M., Diaz P., Pastor F.I., 2005, Paenibacillus barcinonensis sp. nov., a xylanase-producing bacterium isolated from a rice field in the Ebro River delta., Int. J. Syst. Evol. Micr. vol. 55, 935-939.

Sharma N., Mahajan S., Sharma N., 2013, Evaluation of different pretreatments versus forest wood waste and its selection as a solid substrate for enhanced cellulase production by Paenibacillus mucilaginous B5, Asian J. Ex.p Biol. Sci. vol. 4, 226-236.

Subramaniyan S., Prema P., 1999, Cellulase-free xylanases from Bacillus and other microorganisms, FEMS Microbiol. Lett. vol. 183: 1-7.

Święcicka I., Hauschild T., 1996, Genus of Bacillus occurrence and role in natural environments, Post. Mikrobiol, vol. 35: 27-41. (in Polish).

Ten L.N, Sang-Hun B., Wan-Taek I., Larina L.L., JungSook L., Hee-Mock O., Sung-Taik L., 2007, Bacillus pocheonensis sp. nov., a moderately halotolerant, aerobic bacterium isolated from soil of a ginseng field, Int. J. Syst. Evol. Micr. vol. 57, 2532-2537.

Waeonukul R., Kyu K.J., Sakka K., Ratanakhanokchai K., 2009, Isolation and characterization of a multienzyme complex (cellulosome) of the Paenibacillus curdlanolyticus B-6 grown on Avicel under aerobic conditions, J. Biosci. Bioeng, vol. 107, 610-614.

Vardavakis E., 1989, Seasonal fluctuations of aerobic cellulolytic bacteria, and cellulase and respiratory activities in a soil profile under a forest, Plant Soil, vol. 115, 145-150.

Velázquez E., de Miguel T., Poza M., Rivas R., Rosselló-Mora R., Villa T.G., 2004, Paenibacillus favisporus sp. nov., a xylanolytic bacterium isolated from cow faeces, Int. J. Syst. Evol. Micr. vol. 54, 59-64. 


\section{Synthesis of cellulase in the cultures of bacteria Paenibacillus sp. isolated from the rhizosphere}

\section{Summary}

From the rhizosphere soil of apple, cherry and strawberry fertilized with composts on the basis of brown coal fine with the addition of mycelium from Basidiomycota, 6 strains of facultative anaerobic, spore-forming and able to degrade cellulose bacteria were isolated. On the basis of morphology and 16S rRNA sequences the isolates were classified into Paenibacillus sp. In the selective media supplemented with filter paper (FP) and carboxymethylcellulose (CMC) strains, which synthesize cellulolytic enzymes responsible for the hydrolysis of amorphous and crystalline cellulose were tested. After 14 and 28 days culture in the medium with CMC tested isolates produced similar amounts of carboxymethylcellulase (CMCase) respectively $0-10,87 \mathrm{mU}$ and 10,73-21,13 $\mathrm{mU}$. The highest synthesis of the enzyme, which saccharifying of cellulose (FPase) was found in 14-day culture of $P$. lautus EG_11 - 75,6 mU, Paenibacillus sp. EG_17 - 57,6 mU and P. woosongensis EG_15 - 38,9 mU. In the medium supplemented with FP, the highest synthesis of the CMCase and FPase reported in cultures of $P$. lautus EG_11, it was respectively 79,85 and $118,83 \mathrm{mU}$.

\section{Key words}

CMCase, FPase, Paenibacillus 